\title{
"A nosotras nos han sentenciado a abrazar estos pedacitos de cartón, de papel, que traemos con nosotras que son las fotos de nuestros hijos": Entrevista a María Herrera Magdaleno, activista en la búsqueda de personas desaparecidas en México
}

\begin{abstract}
"We were doomed to search and hug these pieces of paperboard that we bring with us: the photos of our children": Interview with Maria Herrera Magdaleno, activist in the search of missing persons in México
\end{abstract}

\section{Carlos Gutiérrez Rodríguez}

Universidad Nacional de La Plata, Argentinal Universidad Nacional de Colombia, Colombia

cagutrod@gmail.com

\author{
María Emilia Nieto \\ Universidad Nacional de La Plata/CONICET, Argentina \\ mariaemilianieto@gmail.com
}

\section{Resumen:}

Entrevista realizada en Buenos Aires el 22 de noviembre de 2018, a María Herrera Magdaleno, madre de personas desaparecidas en México y activista por los derechos humanos, donde presenta las luchas del movimiento de familiares de desaparecidos en México y las labores llevadas adelante por la Cuarta Brigada Nacional de Búsqueda de Personas.

Palabras Clave: Desaparición forzada, Familiares de desaparecidos, Violencia estata, Memoria.

\section{ABstract:}

Interview with María Herrera Magdaleno, in Buenos Aires, November 22, 2018. She is mother of missing people in México and a Human Rights activist. In this document she shows the demands of the missing relatives movement in México and the tasks of the Forth National People Search Brigade.

KEYWORDS: Forced disappearance, Relatives of missing people, Estate violence, Memory.

\section{Presentación}

La historia reciente de América Latina está marcada por la desaparición forzada de personas, pero también por familiares que, colectivizando el dolor, salen a las calles y se organizan para buscar a sus seres queridos, desplegando diferentes repertorios de acción que tienen como eje las demandas por verdad y justicia; en una lucha contra el miedo, la violencia y el olvido.

Tal es el caso de María Herrera Magdaleno, madre de cuatro hijos desaparecidos en México y una referente de la resistencia a la violencia generalizada y las violaciones a los derechos humanos que hoy se viven en dicho país. María participó en la fundación de la organización de Derechos Humanos, Familiares en Búsqueda María Herrera que impulsó en el año 2014 la conformación de la Red de Enlaces Nacionales, con el objetivo de nuclear los más de cincuenta colectivos de familiares de todo el país.

Los comunicados de esta organización señalan que sus hijos/as, sumados a otros miles de personas, desaparecieron en el Estado de Guerrero en un contexto de violencia incrementada desde 2006 en el marco del gobierno del presidente Felipe Calderón Hinojosa, que profundizando la política de "guerra contra el crimen organizado" desplegó una estrategia de seguridad conocida en México como "la guerra contra el narco". La misma implicó el despliegue de fuerzas militares en el territorio nacional, con el ánimo de cumplir funciones que corresponden a cuerpos civiles de seguridad, al tiempo que sustituyó a titulares de las instituciones de seguridad pública estatales por militares en activo y en retiro. La organización concluye 
que esta militarización se tradujo en un aumento significativo de las violaciones a los derechos humanos. La actitud negligente del Estado respecto a las denuncias de desaparición forzada ha devenido en que miles de familias vivan escenarios de incertidumbre frente a la ubicación de sus familiares, sin acceso a verdad ni a justicia (Familiares en Búsqueda María Herrera, 2018).

Ante tales circunstancias, como resultado de iniciativas ciudadanas, surgió en 2011 el Movimiento por la Paz con Justicia y Dignidad, que sirvió como un espacio para la organización de familiares. En este marco, el Movimiento por Nuestros Desaparecidos en México, tuvo una participación activa en la elaboración de la Ley de Desaparición Forzada, que aun con sus límites expresa una de las primeras conquistas de este movimiento. El trabajo de Familiares en Búsqueda María Herrera ha aportado, en este camino, a la orientación y empoderamiento de las familias de personas desaparecidas, vinculándolas a los procesos llevados a cabo por la Red de Enlaces Nacionales (REN) en la cual se nuclean colectivos de familiares de dieciocho estados mexicanos.

Asimismo, ha impulsado la conformación de la Brigada Nacional de Búsqueda de personas Desaparecidas que despliega diferentes tareas vinculadas al desarrollo de programas de acompañamiento psicosocial a familiares de víctimas de desaparición forzada, a través de la organización Uniendo Cristales; la elaboración y recopilación de documentación de los diferentes casos, que hasta el momento suman más de cincuenta y permiten la realización de diagnósticos locales; así como lleva adelante ejercicios de presión política, cumpliendo un rol fundamental en la coordinación y organización de los grupos de búsqueda de personas desaparecidas, nacidos como iniciativas de la sociedad civil. Estos espacios configuran una nueva trama de participación en las comunidades, generando procesos de organización locales, donde reaparece la dimensión de lo público y comunitario en ejercicios activos de ciudadanía.

Entrevistamos a María en noviembre de 2018, en su visita a Buenos Aires, Argentina, en la que buscó difundir las graves violaciones a derechos humanos que ocurren en su país y articular redes de solidaridad con otras organizaciones en América Latina. Espacios como este pueden tender puentes para el diálogo y la escucha, aportando a la comprensión de la realidad mexicana para pensar nuevos horizontes en la lucha contra la violencia estatal y la desaparición de personas. Recordando que "la narración no es una mera representación de los eventos de la historia: es ella misma un evento de la historia, es algo que las personas hacen en el transcurso del tiempo y tiene efectos sobre los comportamientos colectivos e individuales" (Portelli, 2004, p. 36).

\section{Comenzamos contándole a María sobre la Maestría en Historia y Memoria, y nuestro interés en visibilizar este tema:}

M: Gracias, pues precisamente nuestra inquietud de llegar hacia ustedes aquí es que se sepa la verdad y que de una forma u otra las acciones que ustedes hacen aquí, pues hacerlas presentes a lo largo de nuestros organismos y a su vez que lo que hacemos allá ustedes lo tomen también, en algo les pudiese servir. Estamos dispuestos y nuestro principal objetivo es hacer enlaces con todos los lugares y todas las asociaciones posibles para de esa manera fortalecernos en nuestras luchas ¿no? Ese es nuestro principal objetivo.

\section{María, para empezar, queríamos preguntarte ¿quién sos vos?}

M: Mira yo soy una madre mexicana, tengo 4 hijos desaparecidos: Raúl y Jesús Salvador, desaparecidos en Atoyac de Álvarez Guerrero, el 28 de agosto de 2008. Y siempre he mencionado que después de una intensa búsqueda por mis dos hijos y sus cinco compañeros de trabajo, porque ellos viajaban con cinco personas más, decidimos regresarnos a casa, pero sin imaginar la situación tan cruel, tan sangrienta, que se estaba viviendo en México, porque yo soy de una provincia del Estado de Michoacán que se llama Pajacuarán y ahí no llegan noticias, definitivamente no se sabe nada, es una provincia muy pequeña.

Después de hacer un recorrido y buscar sin ninguna respuesta, sin ningún resultado, a mis hijos, yo me sentía desanimada, frustrada. Mis otros hijos a su vez en casa, viendo que ya no había posibilidades para seguir 
buscando a sus hermanos, decidieron de nuevo salir a trabajar para apoyar a su familia, porque ellos están casados, tienen sus hijos, su esposa y ahora sí que las condiciones económicas ya no eran nada favorables y aparte querían seguir buscando a sus hermanos. Salen a trabajar: Gustavo, Luis Armando, el esposo de una nieta y un sobrino. Ahora con rumbo a Veracruz, porque debo mencionarles que mis hijos se dedicaban a la compra y venta de oro y trabajaban en diferentes partes de la república. Así que decidieron irse a Veracruz, pero curiosamente el 22 de septiembre del 2010 Gustavo se comunicó con su esposa para hacerle saber que en esos momentos pasó por ahí el Huracán Karl, que hizo destrozos en todo el estado de Veracruz y averió uno de los puentes por los cuales tenían que pasar mis hijos. Como ese puente estaba destruido todo el mundo estaba dando vuelta por otro lugar y que iban a tardar en llegar a su destino, fue la última conversación que tuvo con su esposa.

De ahí ya no hubo más comunicación y fue algo muy extraño porque ellos en la noche siempre acostumbraban llamarles a sus esposas y porque el niño estaba pendiente, no se dormía si su papá no le hablaba, lo cual ya no sucedió. A Gustavo y Luis Armando me los desaparecieron en Poza Rica, Veracruz. Ahí Gustavo tuvo la última conversación con su esposa. A partir de ahí pues yo me sentí derrumbada, me sentí que ya no podía, no sentía fuerza para seguir luchando. Sin embargo, lo tuve que hacer. Me levanté me puse de pie y a seguir buscando a mis hijos, porque obvio que mis hijos, los que me quedaban: Juan Carlos, Rafael, Miguel Ángel, nunca dejaron de buscar a sus hermanos, ellos siempre estuvieron pendientes y los siguieron buscando, pero yo me dejé caer por una temporada. Después me adherí de nuevo a la búsqueda y aquí empezó de nuevo un peregrinar, que ya no sabes qué hacer, porque sientes que no eres escuchada en ninguna parte. Al menos dentro del gobierno nos fuimos dando cuenta de que no estaban haciendo nada, que jamás lo hicieron y que estoy segura de que nunca lo van a hacer, me refiero al gobierno anterior. Ahorita con este nuevo gobierno que va a entrar el 1 de diciembre, tenemos la esperanza de que hagan algo, porque consideramos que hemos sido escuchados. Hemos tenido algunas reuniones con el equipo del nuevo gobierno y han estado muy receptivos, muy atentos a todo lo que nosotros les estamos planteando. Aunque les puedo asegurar que ya tuvimos una primera desilusión, porque lo que nosotros hemos estado pidiendo al gobierno mexicano es que concentre a todo el Ejército, no queremos el Ejército en las calles. No queremos la marina en las calles, porque nosotros sabemos que muy lejos de cuidarnos, son los que nos oprimen, los que nos han acabado, porque han participado muchos de ellos en la desaparición de nuestros hijos.

Ahorita nada más le cambiaron de nombre, pero sabemos que es el mismo Ejército, son las mismas personas y para nosotros eso nos está bajando la moral, porque eso nos da indicios de que nos oyeron, pero no nos escucharon, no pusieron atención o no quieren hacer las cosas como se las estamos pidiendo. Ahora sí estamos atentos a ver qué es lo que va a pasar con este nuevo gobierno, lo que sí estamos haciendo saber es que no fue un cheque en blanco el que la sociedad les entregó. Queremos un cambio sistemático, verdadero y queremos decirles que la forma de ofrecernos la paz es cumpliendo con la ciudadanía, siendo atentos con todas las necesidades que les hemos puesto sobre la mesa y que empiecen a trabajar. Inclusive les hemos dicho que tomen en cuenta todo este trabajo que venimos realizando como colectivos, para que ellos a su inicio no empiecen de cero, que vean este trabajo, lo valoren y lo protejan.

\section{Usted nos contó que quiere que se sepa la verdad, le quisiéramos preguntar ¿por qué sus hijos fueron desaparecidos, quién los desapareció?}

M: Mira, nosotros sabemos quién desapareció a mis hijos. Los de Guerrero tenemos los nombres de las personas que participaron en ello, es un policía ministerial, era el encargado de Policía Ministerial en su momento y al cual jamás se le ha molestado para llamarlo a cuentas, para que rinda información. Se llama Erik Montufar Mendoza. El comandante que trabajaba en turno en esos momentos, creo que ya lo mataron, ya no existe. No sabemos quién lo haya matado o por qué, lo que sí sabemos es que estando esta persona al mando no desaparecieron nada más a mis hijos, hubo varias desapariciones en Guerrero y pese a eso sigue trabajando dentro del gobierno, así que no se le ha molestado para nada absolutamente. 
En el caso de mis otros dos hijos en Poza Riza, Veracruz, de igual manera intervinieron policías, fue la policía la que los interceptó y a partir de ahí mis hijos desaparecieron. Tenemos entendido que es la policía quien los entrega a los grupos criminales. Por eso yo siempre he gritado a los cuatro vientos que no es el crimen organizado, como el gobierno nos ha hecho sentir o pensar, es el crimen institucionalizado, porque dentro de las instituciones de gobierno se les da cierto poder. El sólo hecho de callar y de no buscar, de no hacer lo que les corresponde, con eso están encubriendo a toda esta gente. Entonces son partícipes de todas estas desapariciones. Forman parte de esa estructura.

Con el paso del tiempo nos hemos ido dando cuenta que uno de los grupos criminales más sangrientos que son los Zetas, salieron precisamente de las estructuras de gobierno, son personas que fueron adiestradas para las armas y el desempeño de este tipo de criminalidad, y ellos saben. Sin embargo, hasta la fecha no han hecho absolutamente nada. Es lo que te decía del gobierno que va a entrar en acción el 1 de diciembre, tenemos cierta confianza ¿no? porque de una forma o de otra, nosotros vamos a seguir insistiendo y vamos a seguir colaborando con lo que podamos. Haciendo todo lo humanamente posible por llegar a descubrir la verdad. La verdad es que a nuestros hijos los asesinan, se los llevan y los desaparecen, pero nosotras estamos dispuestas a dar con la verdad ¿cómo? Buscándolos.

Y de hecho lo estamos haciendo, hemos encontrado infinidad de restos que te hablan de una verdad, te están diciendo lo que pasó. Aquí el verdadero problema es que no hay manera de darles identidad, no hay manera de hacer llegar esos restos a los hogares y es lo que estamos esperando.

Porque yo cuando salgo a las calles a gritar con mis compañeras y les grito ¡Vivos se los llevaron, vivos los queremos! Créanme que a mí se me hace un nudo en la garganta y lo hago para gritar junto con ellas, porque tengo que estar del lado de ellas, pero la verdad yo siento que mi corazón se estruja, porque yo sé de antemano que mis hijos lo más probable es que ya no estén con vida. Yo los busco bajo la tierra.

Ahorita yo lo que le pido al gobierno mexicano y el apoyo que yo pido a toda la sociedad es que me ayuden a rescatar sus restos, porque si ya me les dieron una muerte indigna, quiero que me ayuden a darles una sepultura digna. Y esto a mí me va a hablar mucho de la memoria, porque necesito tenerlos conmigo, necesito darles su identidad, que me la están arrebatando, porque mis hijos como todo ser humano tienen un nombre, un apellido, una madre que los está buscando, una esposa que los está esperando y unos hijos que están esperando su retorno. Yo quiero llevarlos como estén, quiero llevarlos a mi casa, así como a los miles de desaparecidos que tenemos en México, porque esta es la única forma de satisfacer esta búsqueda tan infructuosa que hasta la fecha no hemos podido lograr. En algunos casos se han entregado algunos cuerpos, pero son relativamente pocos para este gran esfuerzo que se ha hecho y para todo lo que hemos venido haciendo. Sé que son muy pocos, pero espero que con la ayuda de la sociedad, sobre todo ahora que estamos en estos espacios, que hemos tenido la oportunidad de estar, es lo que estamos pidiendo: ayuda para poder tener un banco de genética, que salga de la sociedad, que no pertenezca al gobierno porque el gobierno lo va a emplear para sus fines. Nosotros necesitamos algo que se pudiera adaptar en alguna de las universidades que tenemos, para que sea un trabajo de verdad confiable, que es lo que necesitamos.

\section{Vos recién hablabas de tus compañeras, de ese colectivo ¿son la mayoría mujeres, son madres, son familiares? ¿Cómo está conformado?}

Generalmente quienes buscamos a nuestros hijos, en su mayoría, somos mujeres, y esto está visto no nada más a nivel nacional sino también a nivel internacional. Los hombres, generalmente, yo no digo que no quieran a sus hijos, no digo que no los necesiten, lo más seguro es que sí y una muestra de ello es que he conocido el fallecimiento de más hombres que de mujeres. Yo del Movimiento Por la Paz, a Nepomuceno Moreno, uno de nuestros compañeros lo mataron en la lucha, porque lo mataron frente al Palacio de Gobierno, en Sonora, a él le quitaron la vida, pero a partir de ahí, pues el primero que murió sin saber de mis hijos, fue mi esposo. De ahí del pueblo, a los seis meses que me desaparecen a mis dos primeros hijos, a mi esposo le da un infarto. En seguida murió otro compañero también de ahí del mismo pueblo, se llama Javier Cortez, le desaparecieron a dos de sus hijos y de igual manera se fue sin saber de sus hijos. Después 
conocimos al señor Roberto Galván, dentro del Movimiento por la Paz, también ese señor estuvo en la lucha y anduvo con nosotros, pero como que los hombres en este sentido son menos fuertes, porque también se fue sin saber de su hijo.

Tenemos a otra persona, también hombre, dentro del movimiento, no sé si era apellido o apodo, lo llamábamos Palomo, este señor también estuvo en la lucha con nosotros. También murió. Entonces eso a mí me da a entender que los hombres como que tienen menores capacidades emocionales o no sé cómo decirlo, lo saben encauzar menos. Nosotros por ejemplo por medio del llanto, por medio de salir a gritar, por medio de dar a conocer lo que estamos viviendo, eso nos va reanimando, no da fuerzas para seguir en la lucha.

Los hombres son más callados, sufren más en silencio y repito yo mi admiración por todas esas personas, esos hombres que han quedado en la lucha, pero por otros tantos que sé que están sufriendo en silencio la ausencia de sus hijos y que no por eso los voy a menospreciar o a bajar su interés. Sé de antemano que si no lo hacen es porque o tienen que sustentar la familia, pero generalmente somos más madres las que andamos en todos los espacios.

\section{¿Conocías la experiencia argentina de las Madres y Abuelas de Plaza de Mayo?}

M: Mira, yo había escuchado hablar de ellas y de hecho sí te llama la atención, porque esto es un acto admirable, de cómo fueron ellas haciendo un esfuerzo, una lucha constante, la cual fue visibilizada yo creo que en todos los niveles. Cuando yo escuchaba hablar de ellas pues yo decía, que admirables estas señoras ¿no? y sientes desde ahí un respeto infinito por lo que están haciendo. Cuando ya te pasa esto ahora sí que entiendes a la perfección los porqués y ya no es nada más una admiración y un respeto, sino es algo que lo haces tuyo y que lo compartes de tal manera que aprendes, las sientes como unas maestras.

Y dices tú: si estas personas han llevado una lucha por tantos años y han hecho un esfuerzo sobrehumano, por qué razón no lo puedo hacer yo ¿no? y eso mismo te va haciendo crecer, te va fortaleciendo y te va animando a seguir en este camino donde la verdad hay ocasiones en que siente uno que llega un momento que no sabes para dónde caminar o cómo hacerlo. Afortunadamente yo las conocí, conocí a unas de ellas en México, no recuerdo si fue en el 2012, creo que sí, estuvieron en el claustro de Sor Juana y ahí pudimos conocernos un poquito, pues no fue un diálogo porque la verdad no fue un diálogo, pero ahí las pude escuchar, las conocí. Pero siempre albergaba yo dentro de mí la esperanza de algún día poderlas ver más de cerca, estar con ellas y decirles de viva voz que las admiro, las respeto y que son personas muy queridas. No nada más por llevar este mismo dolor de nosotras, sino por su lucha, como te digo.

Ahorita afortunadamente me tocó estar con la señora Estela de Carlotto, mi interés es estar con las Abuelas de Plaza de Mayo, estar con ellas. De hecho, el año pasado yo tenía programada una visita aquí a Argentina, única y exclusivamente para estar con ellas, porque yo la verdad mi mente no me daba para pensar que pudiese tener la oportunidad de estar en un espacio como éste o como en el que acabo de estar, donde estuvo toda la sociedad de diferentes partes del mundo ${ }^{1}$, nunca lo imaginé, créanmelo. Pero viendo que al llegar aquí nos han tendido sus brazos, su cariño hacia nosotros, pues para mí no se imaginan, siento como que estoy en un sueño, que esto no es realidad. Sin embargo, veo que para mí estas no son casualidades. Ya lo decía yo, que son diosedades, porque como que dios va acomodando todo en su justa dimensión y el hecho de estar aquí yo siento que son pasos muy firmes, porque estoy con gente que ha vivido esta misma situación, que me entiende perfectamente y a su vez la entiendo ¿no? y esto de fortalecer estas luchas para mi es prácticamente lo más importante.

\section{Recién antes de empezar esta entrevista le comentábamos sobre el caso de las llamadas Madres de Soacha, en Colombia ¿las conoce también?}

M: Las conocí por medio de los mismos colectivos, donde a veces nos reunimos de los diferentes grupos y me comentaban que a estas madres les asesinaban a sus hijos, los tomaban de las calles, de donde podían, luego los vestían de militares y los acusaban de lo que ellos querían. Es poco lo que sé, la verdad. Lo que sí les puedo decir es que en el momento que recibimos esta información, cuando nos estaban platicando de qué forma lo hacían tú te sientes con un coraje que dices ¡no!, pero de nuevo, admiro la valentía de estas madres 
que lucharon para descubrir y para dar a conocer a la sociedad el verdadero motivo de la desaparición de sus hijos y cómo no se cansaron de buscar y pese a haber sido señaladas de esa forma a estas madres no les importó.

Es lo que yo les digo a mis compañeras cuando van a presentar sus denuncias, siempre les decía yo: miren hay unas madres que incluso se los vistieron, les quitaron la ropa y se los vistieron de militares, para hacer creer otra cosa y ellas no descansaron hasta sacar a luz la verdad. Eso mismo nos queda a nosotros, hasta que nuestros hijos no los acusen de ser lo peor, tenemos que demostrar su inocencia, tenemos que limpiar su imagen y tenemos que dar a conocer la forma de vida que llevaban nuestros hijos. Hacerle ver a la sociedad quiénes eran, cómo vivían y qué hacían, para que la sociedad no esté queriéndolos involucrar en algo que no es. Todas estas luchas, como les digo yo, siempre las he abrazado, las admiro y voy aprendiendo algo de todas estas mujeres valientes, que pese a este dolor que nos embarga porque es algo de lo más tremendo que se puedan imaginar. Nadie de la sociedad es capaz de entender el dolor que se vive cuando te arrebatan un hijo, aunque mucha gente nos sigue, nos apoya y yo creo que lo hacen pues también para en cierta forma sentir que están haciendo algo por los suyos, para que nada de esto siga pasado. Y la sociedad que se une yo creo que lo hace precisamente por esto: porque no se quieren ver en el papel que estamos nosotras.

Yo siempre que salgo a las calles les digo, a nosotras nos han sentenciado a abrazar estos pedacitos de cartón, de papel, que traemos con nosotras, que son las fotos de nuestros hijos, sintiendo que son nuestros hijos lo que traemos alrededor. Y a la sociedad, a las personas que me escuchan yo les digo: ustedes que tienen la oportunidad de abrazar y de apapachar a sus hijos ¡háganlo! pero siempre que lo hagan piensen por cuánto tiempo los pudieran tener con ustedes, porque si ustedes llegasen a pensar que va a haber momentos, si no hacen nada para apoyar, para evitar que esto siga pasando, va a llegar un momento en que se van a ver en esta misma situación y eso es algo que no queremos que pase, queremos poner al servicio de la humanidad nuestro dolor, nuestro sentir para que lo tomen como suyo y para que de esta forma eviten por todos los medios llegar a verse en esta situación.

Yo creo que de todas las acciones que pudiesen haber, éstas son las más reprobables, las más crueles, porque siempre que hablan de la criminalización, siempre que hablan de, la verdad no sé cómo expresarme, yo siempre les digo que lo que nosotras las madres estamos viviendo, los familiares, es un martirio. Tanto por parte del gobierno, como por parte de la sociedad cuando vemos que no entienden y no quieren informarse y que no hacen nada ¿no? nos sentimos en cierta forma rechazados y el hecho de ver tal deshumanización en la sociedad sentimos que eso lo hacen en contra nuestra ¿no? muy lejos de darles el apoyo de ver en qué forma entre todos logramos bajar los niveles de violencia en estos lugares.

Veo esa pasividad, ese desinterés que te da tristeza y eso mismo te hace muchas veces, no digo bajar la guardia, pero si desanimarte. Sentir en algunas ocasiones que no tiene sentido tanto sacrificio, porque nosotros pese a la pérdida de nuestros seres queridos seguimos en pie de lucha. Que bien podría decir por más que luche contra viento y marea yo sé que mis hijos difícilmente los voy a regresar a casa, pero esto que estamos haciendo es precisamente para que a la sociedad ya no le siga pasando esto. Lo hacemos aportando nuestro dolor, nuestro sufrimiento, hacia una causa digna: para evitar que eso siga pasando. Nuestros mensajes son precisamente para eso, para que la sociedad la tome como una información, como una especie de alerta.

Quisiera mandarle un mensaje a toda la sociedad diciéndoles que a partir del 19 de enero del próximo año (2019) va a salir de nuevo la caravana de búsqueda ${ }^{2}$ en pozos clandestinos y queremos que todos los ojos, todos los corazones estén alertas a seguir estas caravanas a fortalecernos desde sus espacios, desde sus trincheras donde están cada uno para que nos apoyen en estas búsquedas. Muchísimas gracias.

\section{REFERENCIAS}

Familiares en Búsqueda María Herrera. (2018). Justificación en contexto de Familiares en Búsqueda María Herrera. México. Recuperado de: http://www.bancariabancario.com.ar/files/shares/5bf7e7a4b583e.pdf 
Olivares Alonso, E. (14 de febrero de 2019). Cuarta brigada destapó negligencia de las autoridades. La Jornada. Recuperado de: https://www.jornada.com.mx/2019/02/14/politica/015n1pol

Portelli, A. (2004). El uso de la entrevista en la historia oral. Anuario de la Escuela de Historia, (20), 35-48. Recuperado de: https://rephip.unr.edu.ar/handle/2133/11964

\section{Notas}

1 Se refiere a la $8^{\circ}$ Conferencia Latinoamericana y Caribeña de Ciencias Sociales. Las luchas por la igualdad, la justicia social y la democracia en un mundo turbulento. Primer foro mundial del pensamiento crítico. Realizada por CLACSO en Buenos Aires, del 21 al 23 de noviembre de 2018.

2 A principios de ese año, la Cuarta Brigada Nacional de Búsqueda de Personas desarrolló sus actividades y encontró evidencias en lugares que ya habían sido previamente examinados por parte del Estado mexicano. El trabajo desarrollado aportó nuevas piezas para identificar puntos en los cuales rastrear posiblemente a personas desaparecidas. Este trabajo fue presentado al nuevo gobierno y se establecieron compromisos, a la espera de cumplirse, para fortalecer la integración entre los colectivos de carácter civil y los mecanismos estatales (Olivares Alonso, 2019). 